\title{
New Money-Making Tactic by Predatory Publishers
}

\author{
Shahryar Sorooshian \\ School of Business, Economics and Law, University of Gothenburg, 41124 Gothenburg, Sweden; \\ sorooshian@gmail.com
}

Received: 17 November 2019; Accepted: 18 December 2019; Published: 23 December 2019

\begin{abstract}
This letter is an inquiry into the money-making by predatory publishers. The author discusses new tactics adopted by a few unprofessional publishers to abuse their authors' trust and make money. To overcome the publication misconduct, the author closes this letter with an alarm for the scientific community to be aware of the new tactics that predatory publishers are using.
\end{abstract}

Keywords: predatory; publisher; copyright; authors

Article publication is a money-making business for many publishers. Hence, the last few years have observed an increased number of predatory publishers [1]. They attempt to take advantage of scholars who are looking for a scholarly publishing platform for presenting their findings [2]. Unrealistic publication and/or submission fees, demanding payments for (unnecessary and/or unlikely) language proofreading and/or manuscript formatting, and additional costs for a fast track review are among the tactics that unprofessional journals may take to make money. However, for the above tactics, the authors have an option to discontinue working with the journal and withdraw their manuscript from publication without paying. Unfortunately, there are a few new tactics in which the authors have no option other than to accept to pay money. Therefore, this article presents potential money-making tactics which recently seem to be employed by a few predatory publishers.

A journal after a normal, or faked, peer-review process can offer publication of the submitted manuscript. In the acceptance email, it will be written that the author needs to pay the publication fee, and sometimes it is with the requirement of submission of the signed copyright form, in order to get the official acceptance letter and further publication actions. Hence, after receiving the requested items, the author will be informed that the accepted manuscript is going to be published in a regular issue; but the scheduled publication time is not for the near future, for example, it can be scheduled for publishing after 24 months from the email date. Additionally, the email from the journal offers a fast publication, even for the coming issue within a few days, with an extra payment. Since the author had signed the copyright transform forms and 24 months waiting was an unexpected and long publication delay, the author had no choice, but to pay the additional fee for the fast-track publication. Likewise, the journal can offer a cancelation charge for withdrawing the manuscript from the publication (and returning the copyright).

The cancelation charge could also be applied as a winning card when the unprofessional journal planned to slow down the review process and decision-making time for the submissions. The review process can be planned to take much longer than the authors expect and of course there will be additional charge if the authors ask for their submission's cancelation or withdrawal.

To conclude, the scientific community are now aware of predatory journals' tactics and this pushes the unethical publishers to find innovative ways to make money. The scientific society should be aware of the new trends of these publication businesses to be able to offer a solution. This letter encourages authors to share the new tactics that they observe from predatory publishers, with the community. 
Funding: This research received no external funding.

Conflicts of Interest: The author declares no conflict of interest.

\section{References}

1. Sorooshian, S. Scholarly black market. Sci. Eng. Ethics 2017, 23, 623-624. [CrossRef]

2. Sorooshian, S. Publication phishing: A growing challenge for researchers and scientific societies. Curr. Sci. 2016, 110, 766-767.

(C) 2019 by the author. Licensee MDPI, Basel, Switzerland. This article is an open access article distributed under the terms and conditions of the Creative Commons Attribution (CC BY) license (http://creativecommons.org/licenses/by/4.0/). 